\title{
OPTIMAL OPERATION METHOD OF PROTECTION DEVICES IN PRIMARY FEEDER WITH LARGE SCALE PV SYSTEM
}

\author{
Hu-Dong Lee ${ }^{1}$, Soon-Hwan Kwon ${ }^{1}$, Sung-Sik Choi ${ }^{1}$, Marito Ferreira ${ }^{1}$, \\ Ji-Hyun Park ${ }^{1}$ and Dae-Seok Rho ${ }^{1 *}$ \\ ${ }^{1}$ Department of Electrical Engineering, Korea University of Technology and \\ Education, Korea \\ dsrho@koreatech.ac.kr
}

\begin{abstract}
If large scale PV systems are installed and operated in primary feeder, the bi-directional power flow may be occurred and then the magnitude and direction of fault current can be changed depending on the fault location and point of common coupling of PV system, and time current curve cannot be properly maintained between protection devices. And also, it is difficult to obtain a proper time interval between protection devices because the conventional setting approach is applied even though PV system is installed and operated. Therefore, this paper presents 3 operation modes of setting approach for protection devices considering the operation conditions of PV system to obtain setting values of protection devices. Base on the modes, this paper proposes algorithm to calculate optimal time interval of protection coordination according to introduction capacity of PV system. In addition, this paper performs the modelling of distribution system with PV system and protection devices by using Off-DAS $S / W$, and analyzes the characteristics of time interval between protection devices such as substation relays, reclosers, customer relays, PV customer relays. From the simulation results, it is confirmed that the proposed operation modes and setting approach algorithms are useful and effective to protection coordination in the distribution system with PV system.
\end{abstract}

Keywords-Protection Devices, Distribution System, Over Current Ground Relay(OCGR), Over Current Relay(OCR), Photovoltaic System, Protection Coordination

\section{INTRODUCTION}

Recently, government in Korea have enforced to reduce proportion of thermal power plants and expand renewable energy sources including PV systems and WP systems in order to overcome environmental issues such as climate change and fine dust. Also, largescale PV systems have been actively interconnected with distribution system due to government policies to remove restriction requirement of technical guideline for interconnection of less than 1MW of PV systems[1]-[5]. As large scale distributed generators are interconnected with the primary feeder, many problems are being occurred on the protection coordination between protection devices, because the magnitude and direction of fault current are changed depending on the PCC(point of common coupling) of PV system and the fault location of distribution system[6]-[9]. And also, it is difficult to obtain a proper coordination time interval of protection devices because the conventional

Received: May 6, 2019

Reviewed: July 15, 2019

Accepted: August 2, 2019

* Corresponding Author 
setting approach is applied even though large scale PV systems are installed and operated [10]-[11]. Therefore, this paper presents 3 operation modes of protection devices considering the operation conditions of PV system to obtain setting values of protection devices and proposes algorithm to calculate optimal protection coordination time interval [12]-[13]. In other words, the first mode(Case I) is to perform the conventional setting values in the distribution system with PV system and the second mode(Case II) is the setting values of protection devices calculated by the operation condition of PV system in the distribution system with PV system and the third mode(Case III) is the same setting values of protection devices of Case II even though the PV is not operated due to faults or environmental conditions. In addition, based on these operation modes, this paper propose an algorithm for calculating the optimum coordination time interval between substation(S/S) relay and recloser(R/C), R/C and customer relay, and $\mathrm{S} / \mathrm{S}$ relay and customer relay. As a result of the characteristics of coordination time interval between the protection devices by using off-DAS S/W, it is confirmed that the propose operation modes and the algorithm for calculating the coordination time interval between the protection devices are useful for the setting values calculation of protection devices.

\section{SETTING VALUES CHARACTERISTICS OF PROTECTION DEVICES WITH AND WITHOUT PV SYSTEM}

\subsection{OPERATION METHOD OF CONVENTIONAL PROTECTION DEVICES}

2.1.1. SETTING VALUES OF S/S RELAY: The operation time of OCR(Over Current Relay) and OCGR(Over Current Grounding Relay) of the S/S relay are determined according to the guidelines of KEPCO, and its setting values are calculated by CT ratio, instantaneous tap, and time delay tap. CT ratio of $\mathrm{S} / \mathrm{S}$ relay can be obtained by multiplying the rated current of feeder capacity(10MW), by 1.5 times, as shown in Eq. (1).

$$
C T_{\text {ratio, } s}=\frac{P_{L}}{\sqrt{3} \times 22.9 k V} \times 1.5
$$

where, $P_{L}$ is the rated feeder capacity

And, instantaneous taps for phase and ground fault are calculated by more than 1.5 times of the 3 short-circuit current at installation point of forward protection devices(R/C) or by more than 1.4 times of single line ground(SLG) fault current, as shown in Eq. (2).

$$
\operatorname{Tap}_{\text {ins }, s}=I_{F} \times \text { Coef }_{\text {ins }, s} \times C T_{\text {ratio }}
$$

where, $I_{F}$ is fault current of $3 \phi$ short-circuit current or SLG fault current, $\operatorname{Coe}_{\text {ins, }, \text { is }}$ instantaneous tap coefficient according to fault type such as phase fault(1.5) and ground fault(1.4)

In addition, time delay taps for phase and ground faults are calculated by 1.5 times and 0.3 times of rated feeder current respectively, as shown in Eq. (3).

$$
\operatorname{Tap}_{t d, s}=\frac{P_{L}}{\sqrt{3} \times 22.9 \mathrm{kV}} \times \operatorname{Coe} f_{t d, s} \times C T_{\text {ratio }}
$$

where, $\operatorname{Coe} f_{t d, s}$ is coefficient of time delay tap with fault types such as phase fault(1.5) and ground fault $(0.3)$

2.1.2. SETTING VALUES OF R/C: A minimum operating current of $R / C$ with instantaneous and time delay operation characteristics in 3 short-circuit fault is calculated by more than 2.8 times and less than 4.0 times of maximum load current, as shown in Eq. (4). And, minimum operation current for ground fault is obtained by 0.3 times of maximum 
load current as shown in Eq. (5), it is conventionally applied as 70A considering unbalanced load current in the primary feeder. In addition, instantaneous and time delay curves of one $\mathrm{R} / \mathrm{C}$ are usually applied as N2 and N4 respectively, in the case of two R/Cs, N2 and N4 curves are applied for the backward R/C, and N1 and N3 curves are for the forward R/C.

$$
\begin{aligned}
& I_{O P}(P)=2.8 \times I_{M A X} \leq I_{O P} \leq 4 \times I_{M A X} \\
& I_{O P}(G)=I_{M A X} \times 0.3
\end{aligned}
$$

where, $I_{O P}(P)$ is R/C's minimum operation current of phase fault, $I_{O P}(G)$ is R/C's minimum operation current of ground fault and $I_{M A X}$ is maximum load current

2.1.3. SETTING VALUES OF CUSTOMER RELAY: Setting values of customer relay can be calculated by $\mathrm{CT}$ ratio and instantaneous and time delay tap for short-circuit and ground fault. The CT ratio of customer relay can be obtained by multiplying rated current based on contract power of customer by 1.5 times, as shown in Eq. (6). And the instantaneous tap of OCR is calculated by 1.5 times of the 3 short-circuit current at secondary side of customer transformer as shown in Eq. (7), and instantaneous tap of OCGR is generally applied as minimum tap of 10A. In addition, the time delay taps of OCR and OCGR are calculated by 1.5 and 0.3 times of maximum load current respectively, as shown in Eq. (8).

$$
\begin{aligned}
C T_{\text {ratio }, c} & =\frac{P_{\text {con }}}{\sqrt{3} \times 22.9 \mathrm{kV}} \times 1.5 \\
\operatorname{Tap}_{\text {ins }, c} & =I_{3 s} \times 1.5 \times C T_{\text {ratio }} \\
\operatorname{Tap}_{\text {td }, c} & =\frac{P_{\text {con }}}{\sqrt{3} \times 22.9 \mathrm{kV}} \times \operatorname{Coe} f_{\text {td }, c} \times C T_{\text {ratio }}
\end{aligned}
$$

where, $P_{c o n}$ is contract power, $I_{3 s}$ is $3 \phi$ short-circuit current on secondary side of customer transformer and $C_{t d, c}$ is coefficient of time delay tap for customer relay with phase fault(1.5) and ground fault $(0.3)$

\subsection{OPERATION METHOD OF SETTING VALUES CONSIDERING PV SYSTEM}

\subsubsection{SETTING VALUES OF S/S RELAY}

Setting values for OCR and OCGR of S/S relay considering PV system are calculated by $\mathrm{CT}$ ratio, instantaneous tap and time delay tap as same as conventional approach in Section 2.1.1. First, the CT ratio can be obtained by 1.5 times of the modified current which is subtracting capacity of PV system from rated capacity of feeder(10MW), as shown in Eq. (9). And the instantaneous taps of OCR and OCGR are calculated by more than 1.5 times of 3 short-circuit current at installation point of forward protection devices(R/C) or by more than 1.4 times of SLG current, as shown in Eq. (10). In addition, the time delay taps for OCR and OCGR are calculated by 1.5 and 0.3 times of rated feeder current subtracted by PV system respectively, as shown in Eq. (11).

$$
\begin{aligned}
& C T_{\text {ratio }, s}=\frac{P_{L}-P_{p v}}{\sqrt{3} \times 22.9 \mathrm{kV}} \times 1.5 \\
& \operatorname{Tap}_{\text {ins }, s}=I_{E F} \times \operatorname{Coef}_{\text {ins }, s} \times C T_{\text {ratio }} \\
& \operatorname{Tap}_{t d, s}=\frac{P_{L}-P_{p v}}{\sqrt{3} \times 22.9 \mathrm{kV}} \times \operatorname{Coe} f_{t d, s} \times C T_{\text {ratio }}
\end{aligned}
$$

where, $P_{p v}$ is capaticy of PV system and $I_{E F}$ are fault currents of $3 \phi$ short-circuit and SLG current considering $P_{E}$ 


\subsubsection{SETTING VALUES OF R/C}

Minimum operating currents of $\mathrm{R} / \mathrm{C}$ with instantaneous and time delay operation characteristics in 3 short-circuit fault can be obtained by more than 2.8 times and less than 4.0 times of maximum load current $\left(\mathrm{I}_{\mathrm{MAX}}\right)$ subtracted by rated current $\left(\mathrm{I}_{\mathrm{E}}\right)$ of $\mathrm{PV}$ system, as shown in Eq. (12). And minimum operation current of OCGR is obtained by 0.3 times of maximum load current subtracted by rated current of PV system as shown in Eq. (13), it is conventionally applied as 70A considering unbalanced load current in the primary feeder.

$$
\begin{aligned}
& I_{O P}(P)=2.8 \times\left(I_{M A X}-I_{p v}\right) \leq I_{O P} \leq 4 \times\left(I_{M A X}-I_{P V}\right) \\
& I_{O P}(S)=\left(I_{M A X}-I_{p v}\right) \times 0.3
\end{aligned}
$$

where, $I_{p v}$ is maximum output current of $\mathrm{PV}$ system, $I_{O P}(P)$ is $\mathrm{R} / \mathrm{C}$ 's minimum operation current of OCR, $I_{O P}(G)$ is R/C's minimum operation current of OCGR and $I_{M A X}$ is maximum load current.

\subsubsection{SETTING VALUES FOR RELAY OF CUSTOMER WITH PV SYSTEM}

Setting values for relay of customer with PV system can be calculated by CT ratio and instantaneous and time delay tap of OCR and OCGR as same as conventional approach in Section 2.1.3. First, the CT ratio is obtained by 1.5 times of rated current of PV system, as shown in Eq. (14). And the instantaneous taps of OCR and OCGR are calculated by Eq. (15) as same as conventional approach in Section 2.1.3. In addition, the time delay taps of OCR and OCGR are calculated by 1.5 and 0.3 times of rated current of PV system respectively, as shown in Eq. (16).

$$
\begin{aligned}
& C T_{\text {ratio }, c}=\frac{P_{p v}}{\sqrt{3} \times 22.9 \mathrm{kV}} \times 1.5 \\
& \operatorname{Tap}_{\text {ins }, \mathrm{c}}=I_{3 \mathrm{~s}} \times 1.5 \times C T_{\text {ratio }} \\
& \operatorname{Tap}_{t d, c}=\frac{P_{p v}}{\sqrt{3} \times 22.9 \mathrm{kV}} \times C o e f_{\text {td }, c} \times C T_{\text {ratio }}
\end{aligned}
$$

where, $P_{p v}$ is capaticy of PV system and $\operatorname{Coef}_{t d, c}$ is coefficient of time delay tap for customer relay with PV system, which is 1.5 of OCR and 0.3 of OCGR.

\section{OPERATION ALGORITHM OF OPTIMAL COORDINATION TIME INTERVAL IN PROTECTION DEVICES}

\subsection{OPERATION MODELS FOR SETTING VALUES IN PROTECTION DEVICES}

When large scale PV systems are interconnected and operated in primary feeder, there are three operation modes for setting values of protection devices as follows. In other words, the first mode(Case I) is to perform the conventional setting values in the distribution system with PV system and the second mode(Case II) is the setting values of protection devices calculated by the operation condition of PV system in the distribution system with PV system and the third mode(Case III) is the same setting values of protection devices of Case II even though the PV is not operated due to faults or environmental conditions. Table I shows operation models of setting values for protection devices in primary feeder interconnected with PV system according to three operation modes as mentioned earlier. 
Table I. Operation modes of protection devices

\begin{tabular}{|c|c|}
\hline Operation modes & Contents \\
\hline Case I & Conventional approach \\
\hline Case II & Setting values considering PV system \\
\hline Case III & $\begin{array}{c}\text { Setting values considering PV system } \\
\text { when PV system is not operated }\end{array}$ \\
\hline
\end{tabular}

\subsection{OPERATION ALGORITHM OF COORDINATION TIME INTERVAL}

Based on 3 operation modes for setting values of protection devices as mentioned earlier, the procedure for calculating optimal coordination time interval of protection devices depending on introduction capacity of PV system is represented as follows.

[Step 1] Assume capacity of PV system.

[Step 2] Calculate setting values of $\mathrm{S} / \mathrm{S}$ relay, $\mathrm{R} / \mathrm{C}$, and customer relay by the conventional approach of setting values.

[Step 3] Based on setting values of protection devices at [Step 2], calculate coordination time interval between protection devices including $\mathrm{S} / \mathrm{S}$ relay and $\mathrm{R} / \mathrm{C}, \mathrm{R} / \mathrm{C}$ and customer relay, $\mathrm{S} / \mathrm{S}$ relay and customer relay, by fault current considering $\mathrm{PV}$ system.

[Step 4] Calculate setting values of S/S relay, R/C, and customer relay by the second mode.

[Step 5] Check operation condition of PV system. If it is operated normally, go to [Step 6], and if it is not, go to [Step 8].

[Step 6] Based on setting values of protection devices at [Step 4], obtain the coordination time interval of protection devices by the fault current considering PV system.

[Step 7] Compare coordination time intervals calculated at [Step 3] and [Step 6], select operation mode to have maximum coordination time interval, and go to [Step 10].

[Step 8] Based on setting values of protection devices at [Step 4], obtain coordination time interval of the protection devices by fault current without PV system.

[Step 9] Compare coordination time intervals calculated at [Step 3] and [Step 7], select operation mode to have maximum coordination time interval, and go to [Step 10].

[Step 10] Repeat above process by increasing small amount of PV system, and stop if introduction capacity of PV system reach to maximum value.

The flowchart of the above procedure is demonstrated as shown in Figure 1. 


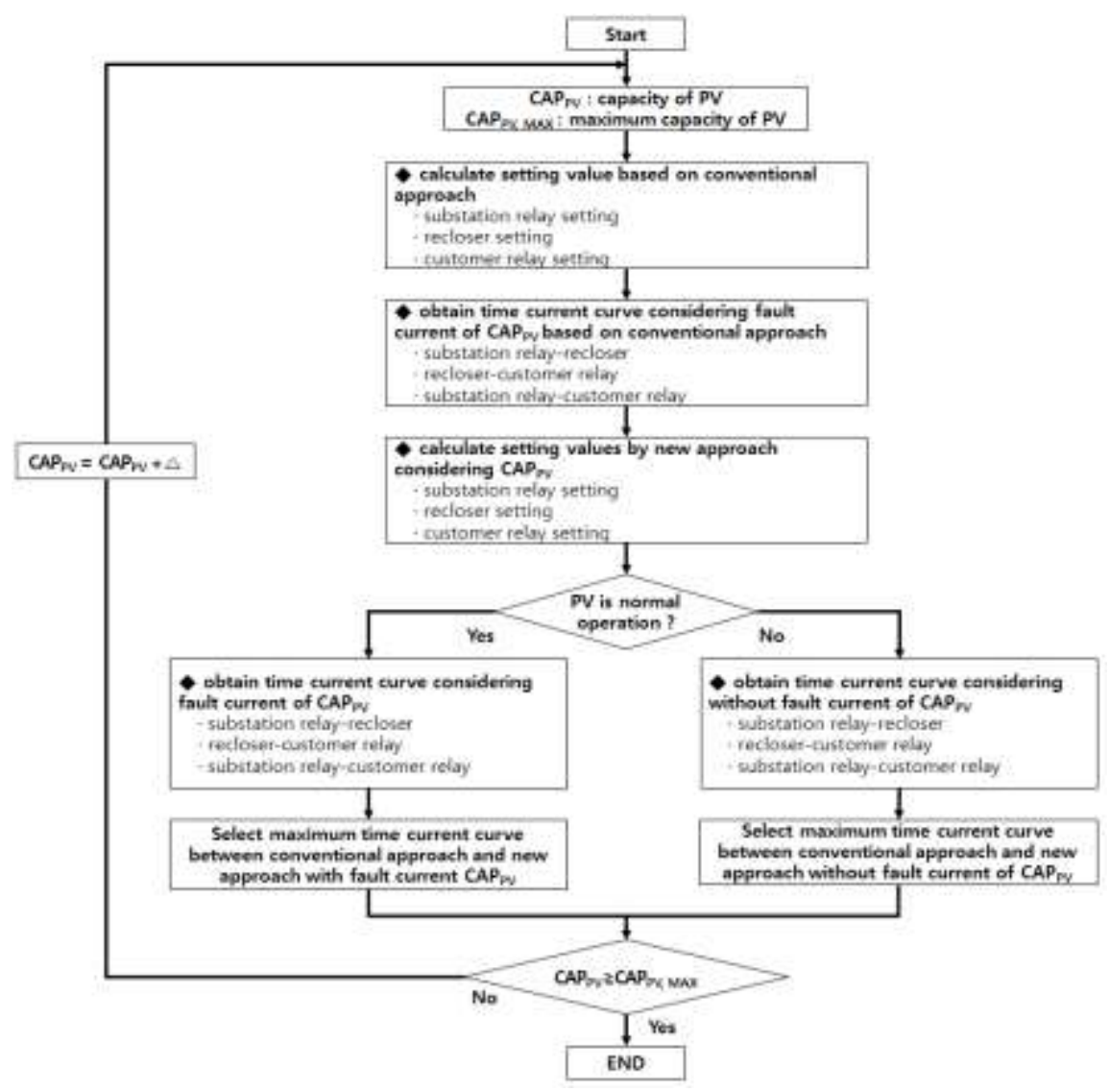

Fig. 1 Operation algorithm of protection coordination time interval

\section{CASE STUDIES}

\subsection{SIMULATION CONDITIONS}

4.1.1. CONDITIONS OF DISTRIBUTION SYSTEM: In order to analyze coordination characteristics between protection devices according to introduction capacity of PV system, this paper performs modeling of distribution system with PV system by using off-DAS S/W, as shown in Fig. 2. Here, this paper assumes that protection devices of distribution system are composed of $\mathrm{S} / \mathrm{S}$ relays, R/Cs, customer relays and $\mathrm{PV}$ customer relays based on the long-distance feeder length which is a total length of $30[\mathrm{~km}]$. In addition, \% impedances for each section is as shown in Table II and S/S and customer relays apply type of GCO-CI II D4 with very inverse TC curve characteristics. And also forward R/C apply TC curves of N1, N3 and backward one is TC curves of N2, N4.

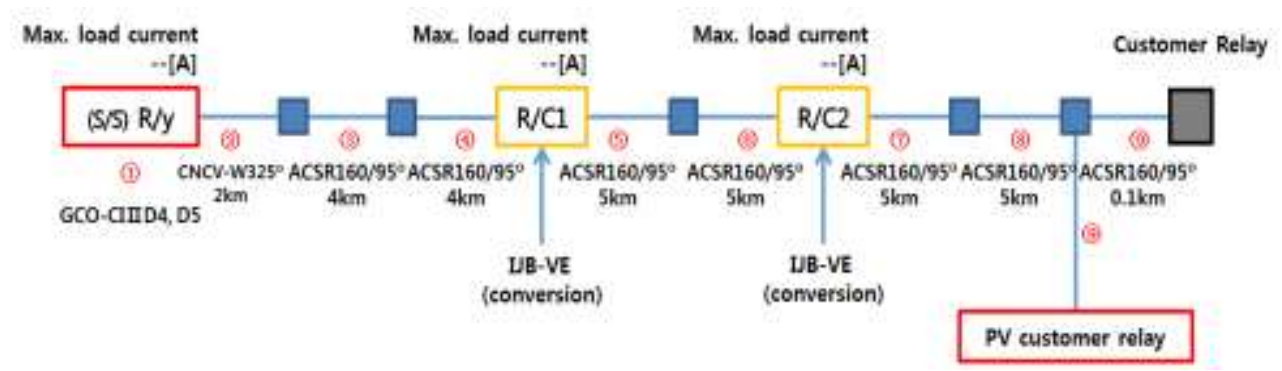

Fig. 2 Modeling of distribution system 
Table II. Contents of distribution system

\begin{tabular}{|c|c|c|c|c|c|}
\hline \multirow{2}{*}{ Section } & \multicolumn{2}{|c|}{$\mathbf{Z 1}(\mathbf{Z 2})$} & \multicolumn{2}{c|}{$\mathbf{Z 0}$} & \multirow{2}{*}{$\begin{array}{c}\text { Length } \\
\text { [km] }\end{array}$} \\
\cline { 2 - 5 } & $\mathbf{\% R}$ & $\mathbf{\% X}$ & $\mathbf{\% R}$ & $\mathbf{\% X}$ & 0 \\
\hline $\mathbf{1}$ & 0.4 & 35.74 & 0.0716 & 17.333 & 2 \\
\hline $\mathbf{2}$ & 2.865 & 4.748 & 8.936 & 3.123 & 4 \\
\hline $\mathbf{3}$ & 13.88 & 29.84 & 47.96 & 117.04 & 4 \\
\hline $\mathbf{4}$ & 13.88 & 29.84 & 47.96 & 117.04 & 5 \\
\hline $\mathbf{5}$ & 17.35 & 37.3 & 59.95 & 146.3 & 5 \\
\hline $\mathbf{6}$ & 17.35 & 37.3 & 59.95 & 146.3 & 5 \\
\hline $\mathbf{7}$ & 17.35 & 37.3 & 59.95 & 146.3 & 5 \\
\hline $\mathbf{8}$ & 17.35 & 37.3 & 59.95 & 146.3 & 0.1 \\
\hline $\mathbf{9}$ & 0.347 & 0.746 & 1.199 & 2.926 & \\
\hline
\end{tabular}

\subsubsection{CONDITIONS OF SETTING VALUES IN PROTECTION DEVICES}

In order to analyze coordination characteristics between protection devices according to introduction capacity of PV system, this paper assumes that it is $0 \mathrm{MW}, 1 \mathrm{MW}, 3 \mathrm{MW}$ and $5 \mathrm{MW}$ and analyzes operation time interval between $\mathrm{S} / \mathrm{S}$ relays and $\mathrm{R} / \mathrm{Cs}, \mathrm{R} / \mathrm{Cs}$ and customer relays, $\mathrm{S} / \mathrm{S}$ relays and customer relays based on the proposed operation modes for setting values of protection devices.

\subsection{SETTING VALUES OF PROTECTION DEVICES}

\subsubsection{SETTING VALUES BY CONVENTIONAL APPROACH}

According to conventional approach of setting values for protection devices, CT ratio of $\mathrm{S} / \mathrm{S}$ relay is obtained by 400/5, which is 378A, 1.5 times of rated current of $252 \mathrm{~A}$, as shown in Eq. (17). However, the CT ratio of 600/5 is conventionally applied with margin for safety in field works. And time delay tap of S/S relay is obtained by $3.15 \mathrm{~A}$, as shown in Eq. (18), and then 4 tap is applied.

$$
\begin{aligned}
& C T_{\text {ratio }, s}=\frac{10 \times 10^{3}}{\sqrt{3} \times 22.9} \times 1.5=378 \mathrm{~A} \\
& \operatorname{Tap}_{t d, s}=\frac{10 \times 10^{3}}{\sqrt{3} \times 22.9} \times 1.5 \times \frac{5}{600}=3.15 \mathrm{~A}
\end{aligned}
$$

As shown in Fig. 3, OCR lever of S/S relay is calculated by 3.8 lever curve that operates at less than $0.5 \mathrm{~s}$ (30Cycles) of $\mathrm{Y}$-axis at 3 short-circuit current $(7,053 \mathrm{~A})$ of $\mathrm{X}$-axis, which is in $\mathrm{S} / \mathrm{S}$ sending point.

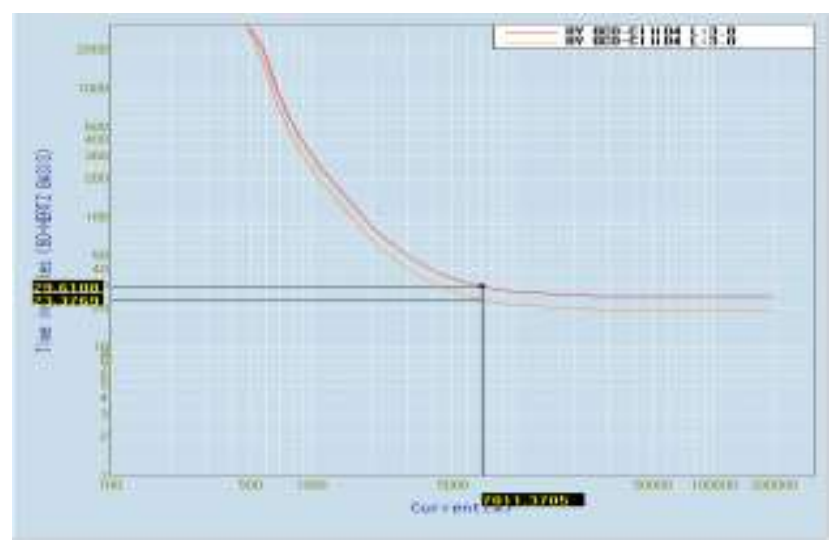

Fig. 3 OCR lever diagram of S/S relay 
And instantaneous and time delay curves of R/C assume as N2, N4 at backward one and $\mathrm{N} 1, \mathrm{~N} 3$ at forward one. In addition, CT ratio of customer relay is applied as 40/5 because it is obtained by $37.8 \mathrm{~A}$ as shown in Eq. (19). And time delay tap of customer relay is obtained by $4.7 \mathrm{~A}$, as shown in Eq. (20) and then 4 tap is applied.

$$
\begin{aligned}
& C T_{\text {ratio }, s}=\frac{1 \times 10^{3}}{\sqrt{3} \times 22.9} \times 1.5=37.8 \mathrm{~A} \\
& \operatorname{Tap}_{t d, s}=\frac{1 \times 10^{3}}{\sqrt{3} \times 22.9} \times 1.5 \times \frac{5}{40}=4.7 \mathrm{~A}
\end{aligned}
$$

As the same as levers of S/S relay in Fig. 3, levers of OCR and OCGR for customer relay is calculated by 4.3 and 1.8 respectively, however they are applied as 0.5 for stable protection coordination. Therefore, setting values of protection devices without PV is shown as Table III.

\begin{tabular}{|c|c|c|c|c|c|}
\hline \multicolumn{2}{|c|}{ Items } & \multirow{2}{*}{$\begin{array}{c}\begin{array}{c}\text { Type of } \\
\text { protection } \\
\text { devices }\end{array} \\
\text { GCO-CI II D4 } \\
\end{array}$} & \multirow{2}{*}{$\begin{array}{c}\begin{array}{c}\text { CT } \\
\text { ratio }\end{array} \\
609 / 5\end{array}$} & \multirow{2}{*}{$\begin{array}{c}\text { Tap } \\
4\end{array}$} & \multirow{2}{*}{$\begin{array}{c}\text { Lever } \\
3.8\end{array}$} \\
\hline & OCR & & & & \\
\hline S/S relay & OCGR & GCO-CI II D5 & $600 / 5$ & 1 & 4.5 \\
\hline \multirow{2}{*}{$\mathrm{R} / \mathrm{C} 1$} & OCR & IJB-VE & \multirow{2}{*}{$\begin{array}{l}\text { Minimum } \\
\text { operation } \\
\text { current }\end{array}$} & 400 & Instantaneous:N2 \\
\hline & OCGR & IJB-VE & & 70 & Time delay:N4 \\
\hline \multirow{2}{*}{$\mathrm{R} / \mathrm{C} 2$} & OCR & IJB-VE & \multirow{2}{*}{$\begin{array}{c}\text { Minimum } \\
\text { operation } \\
\text { current }\end{array}$} & 250 & Instantaneous:N1 \\
\hline & OCGR & IJB-VE & & 50 & Time delay:N3 \\
\hline \multirow{2}{*}{ Customer relay } & OCR & GCO-CI II D4 & $40 / 5$ & 4 & $4.3->0.5$ \\
\hline & OCGR & GCO-CI II D5 & $40 / 5$ & 1 & $1.8->0.5$ \\
\hline
\end{tabular}

Table III. Setting values of protection devices without PV

\subsubsection{SETTING VALUES BY PROPOSED METHOD}

According to new approach of setting values for protection devices, setting values considering $1 \mathrm{MW}$ PV system is demonstrated as shown in Table 4. Time delay tap of S/S relay is determined by tap 4 and OCR lever of S/S relay is calculated by 3.8 as the same as Fig. 3 in section 4.2.1. And instantaneous and time delay curves of backward R/C are assumed as N2, N4 and ones of forward R/C are as N1, N3. Levers of OCR and OCGR for customer relay is calculated by 4.5 and 1.8 respectively, however they are applied as 0.5 for stable protection coordination.

\begin{tabular}{|c|c|c|c|c|c|}
\hline \multicolumn{2}{|c|}{ Items } & Type of protection & CT ratio & Tар & Lever \\
\hline \multirow{2}{*}{ S/S relay } & OCR & GCO-CI II D4 & $600 / 5$ & 4 & 3.8 \\
\hline & OCGR & GCO-CI II D5 & $600 / 5$ & 1 & 4.5 \\
\hline \multirow{2}{*}{$\mathrm{R} / \mathrm{C} 1$} & OCR & IJB-VE & \multirow{2}{*}{$\begin{array}{l}\text { Minimum } \\
\text { operation } \\
\text { current }\end{array}$} & 400 & Instantaneous:N2 \\
\hline & OCGR & IJB-VE & & 70 & Time delay:N4 \\
\hline \multirow{2}{*}{$\mathrm{R} / \mathrm{C} 2$} & OCR & IJB-VE & \multirow{2}{*}{$\begin{array}{l}\text { Minimum } \\
\text { operation } \\
\text { current }\end{array}$} & 250 & Instantaneous:N1 \\
\hline & OCGR & IJB-VE & & 50 & Time delay:N3 \\
\hline \multirow{2}{*}{ Customer relay } & OCR & GCO-CI II D4 & $40 / 5$ & 4 & $4.5 \rightarrow 0.5$ \\
\hline & OCGR & GCO-CI II D5 & $40 / 5$ & 1 & $1.8 \rightarrow 0.5$ \\
\hline \multirow{2}{*}{$\begin{array}{c}\text { PV customer } \\
\text { relay }\end{array}$} & OCR & GCO-CI II D4 & $40 / 5$ & 4 & $1.9 \rightarrow 0.5$ \\
\hline & OCGR & GCO-CI II D5 & $40 / 5$ & 1 & $1.7 \rightarrow 0.5$ \\
\hline
\end{tabular}

Table IV. Setting values of protection devices with PV (1MW) 
In addition, when 5MW PV system is interconnected in primary feeder, setting values for protection devices are obtained as shown in Table V, respectively. As shown in Table 5 , time delay tap for OCGR of $\mathrm{S} / \mathrm{S}$ relay is reduced by tap 1 compared to tap 0.5 in case of 1MW PV system, and also CT ratio of customer relay is changed by 190/5 compared to 40/5 of 1MW PV system. Setting values of other protection devices with 5MW PV system are almost identical with ones of $1 \mathrm{MW}$, therefore it is found that there is no change depending on introduction capacities of PV system.

Table V. Setting values of protection devices with PV(5MW)

\begin{tabular}{|c|c|c|c|c|c|}
\hline \multicolumn{2}{|l|}{ Items } & $\begin{array}{c}\text { Type of protection } \\
\text { devices }\end{array}$ & CT ratio & Tap & Lever \\
\hline \multirow{2}{*}{$\mathrm{S} / \mathrm{S}$ relay } & OCR & GCO-CI II D4 & $600 / 5$ & 4 & 3.8 \\
\hline & OCGR & GCO-CI II D5 & $600 / 5$ & 0.5 & 4.5 \\
\hline \multirow{2}{*}{$\mathrm{R} / \mathrm{C} 1$} & OCR & IJB-VE & \multirow{2}{*}{$\begin{array}{l}\text { Minimum } \\
\text { operation } \\
\text { current }\end{array}$} & 400 & Instantaneous:N2 \\
\hline & OCGR & IJB-VE & & 70 & Time delay:N4 \\
\hline \multirow{2}{*}{$\mathrm{R} / \mathrm{C} 2$} & OCR & IJB-VE & \multirow{2}{*}{$\begin{array}{l}\text { Minimum } \\
\text { operation } \\
\text { current }\end{array}$} & 250 & Instantaneous:N1 \\
\hline & OCGR & IJB-VE & & 50 & Time delay:N3 \\
\hline \multirow{2}{*}{ Customer relay } & OCR & GCO-CI II D4 & $40 / 5$ & 4 & $4.5 \rightarrow 0.5$ \\
\hline & OCGR & GCO-CI II D5 & $40 / 5$ & 1 & $1.8 \rightarrow 0.5$ \\
\hline \multirow{2}{*}{ PV customer relay } & OCR & GCO-CI II D4 & $190 / 5$ & 4 & $1.9 \rightarrow 0.5$ \\
\hline & OCGR & GCO-CI II D5 & $190 / 5$ & 1 & $1.7 \rightarrow 0.5$ \\
\hline
\end{tabular}

\subsection{CHARACTERISTICS OF COORDINATION TIME INTERVAL}

\subsubsection{COORDINATION TIME INTERVAL BETWEEN S/S RELAY AND R/C}

Coordination time interval between $\mathrm{S} / \mathrm{S}$ relay and R/C should be maintained by more than 10cycle according to technical guidelines of KEPCO. Therefore, in order to evaluate a proper coordination between protection devices, coordination time intervals of OCR and OCGR between S/S relay and R/C are demonstrated as shown in Fig. 4 and Table 6, based on the modeling of Off-DAS S/W. The coordination time interval of OCR between S/S relay and R/C is 37.6cycle as shown in Fig. 4(a) and one of OCGR is 26.2cycle in Fig. 4(b). Therefore, it is confirmed that coordination time intervals of OCR and OCGR are kept within proper values according to technical guidelines of KEPCO. From the simulation result of Case II and Case III as the same as Case I, coordination time intervals between protection devices is expressed as shown in Table VI. As shown in Table VI, it is found that coordination time intervals between $\mathrm{S} / \mathrm{S}$ relay and $\mathrm{R} / \mathrm{C}$ for all operation modes are proper to technical guidelines for the all introduction capacities of PV system.

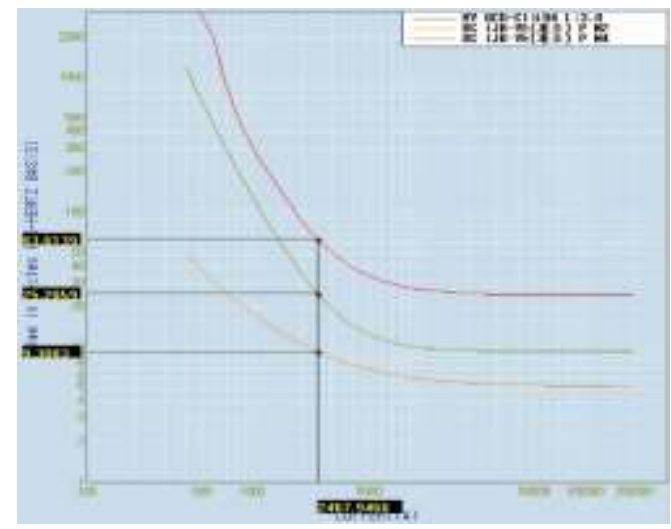

(a) OCR

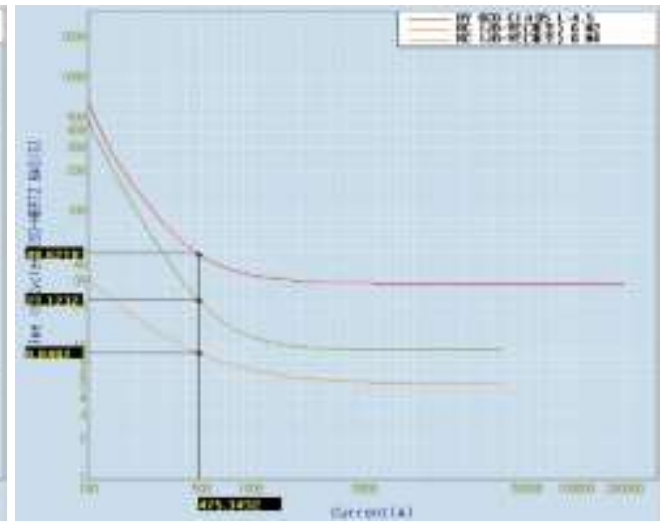

(b) OCGR

Fig. 4 Coordination time interval between $\mathrm{S} / \mathrm{S}$ relay and R/C 
Table VI. Coordination time interval between S/S relay and R/C

\begin{tabular}{|c|c|c|c|c|c|c|c|c|c|c|c|}
\hline \multirow{2}{*}{\multicolumn{2}{|c|}{$\begin{array}{c}\text { Capacity of PV } \\
\text { system(MW) }\end{array}$}} & \multicolumn{10}{|c|}{ Time interval of protection devices(cycle) } \\
\hline & & \multirow{2}{*}{$\begin{array}{c}\mathbf{0} \\
\text { CaseI }\end{array}$} & \multicolumn{3}{|c|}{1} & \multicolumn{3}{|c|}{$\mathbf{3}$} & \multicolumn{3}{|c|}{5} \\
\hline \multicolumn{2}{|c|}{ Operation mode } & & CaseI & CaseII & CaseIII & CaseI & CaseII & CaseIII & CaseI & CaseII & CaseIII \\
\hline \multirow{2}{*}{$\begin{array}{c}\mathrm{S} / \mathrm{S} \\
\text { relay-R/C }\end{array}$} & OCR & 39.5 & 38.9 & 38.9 & 39.5 & 37.6 & 37.6 & 39.5 & 36.4 & 36.4 & 39.5 \\
\hline & OCGR & 159.9 & 111.4 & 111.4 & 132.8 & 82.4 & 26.2 & 29.1 & 66.3 & 25.0 & 29.1 \\
\hline
\end{tabular}

\subsubsection{COORDINATION TIME INTERVAL BETWEEN R/C AND CUSTOMER RELAY}

Coordination time interval between $\mathrm{R} / \mathrm{C}$ and customer relay should be maintained by more than 6cycle according to technical guidelines of KEPCO. In order to evaluate proper coordination between protection devices, coordination time intervals of OCR and OCGR between R/C and customer relay are demonstrated as shown in Fig. 5 and Table 7, based on the modeling of Off-DAS S/W. The coordination time interval of OCR between R/C and customer relay is obtained by 31.4cycle as shown in Fig. 5(a) and one of OCGR is 11.8cycle in Fig. 5(b). Therefore, it is confirmed that coordination time intervals of OCR and OCGR are kept within proper values according to technical guidelines of KEPCO. For 3 operation modes, coordination time intervals between protection devices are obtained as shown in Table VII. In Table VII, it is found that coordination time intervals between R/C and customer relay for 3 operation modes are kept within proper values according to technical guidelines of KEPCO until 3MW of PV system. However, coordination time intervals of OCGR between R/C and customer relay, R/C and PV customer relay are obtained as 5.3Cycle and 4.7Cycle respectively, and it is found that protection coordination of OCGR are not proper if introduction capacities of PV system are more than 5MW. On the other hand, coordination time intervals of OCGR between R/C and customer relay, R/C and PV customer relay for 2 operation modes(Case II and Case III) are kept within proper values according to technical guidelines of KEPCO for 5MW PV system. Therefore, it is confirmed that the proposed operation modes(Case II, Case III) are useful and effective to protection coordination in the distribution system with PV system compare to Case I.

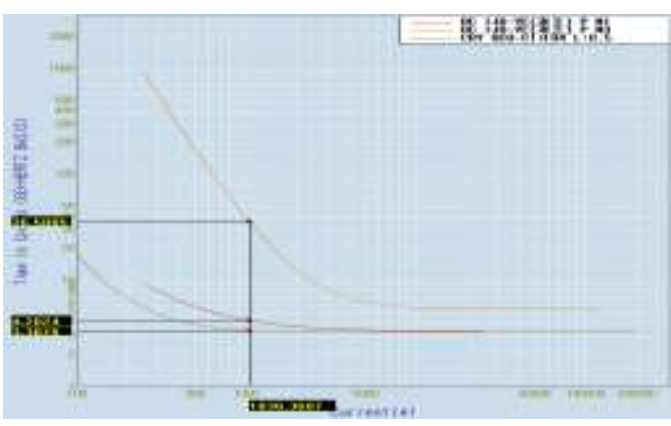

(a) OCR

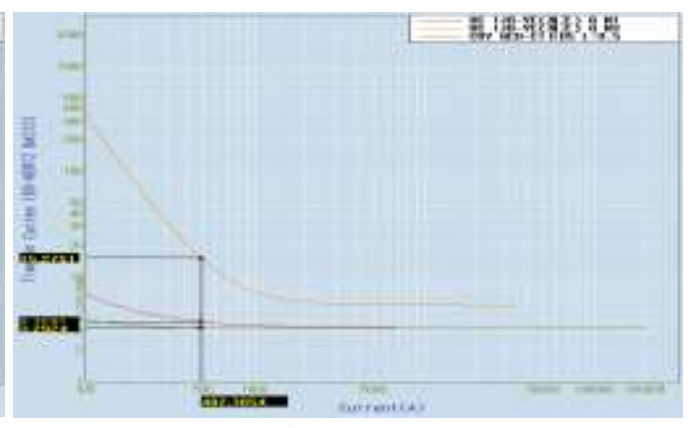

(b) OCGR

Fig. 5. Coordination time interval between $\mathrm{R} / \mathrm{C}$ and customer relay

Table VII. Coordination time interval between $\mathrm{R} / \mathrm{C}$ and customer relay

\begin{tabular}{|c|c|c|c|c|c|c|c|c|c|c|c|}
\hline & & \multicolumn{10}{|c|}{ Time interval of protection devices(cycle) } \\
\hline \multicolumn{2}{|c|}{$\begin{array}{c}\text { Capacity of PV } \\
\text { system(MW) }\end{array}$} & $\mathbf{0}$ & \multicolumn{3}{|c|}{1} & \multicolumn{3}{|c|}{3} & \multicolumn{3}{|c|}{5} \\
\hline \multicolumn{2}{|c|}{ Operation mode } & $\underset{\text { I }}{\text { Case }}$ & $\begin{array}{c}\text { Case } \\
\text { I }\end{array}$ & $\begin{array}{c}\text { Case } \\
\text { II }\end{array}$ & $\begin{array}{l}\text { Case } \\
\text { III }\end{array}$ & $\begin{array}{c}\text { Case } \\
\text { I }\end{array}$ & $\begin{array}{c}\text { Case } \\
\text { II }\end{array}$ & $\begin{array}{c}\text { Case } \\
\text { III }\end{array}$ & $\begin{array}{c}\text { Case } \\
\text { I }\end{array}$ & $\begin{array}{c}\text { Case } \\
\text { II }\end{array}$ & $\begin{array}{c}\text { Case } \\
\text { III }\end{array}$ \\
\hline \multirow{2}{*}{$\begin{array}{c}\mathrm{R} / \mathrm{C}- \\
\text { customer relay }\end{array}$} & OCR & 41.3 & 37.9 & 37.9 & 42.4 & 31.4 & 31.4 & 30.1 & 25.6 & 25.6 & 37.9 \\
\hline & OCGR & 16.9 & 9.3 & 17.4 & 21.6 & 11.8 & 11.8 & 19.7 & 5.3 & 9.0 & 19.3 \\
\hline \multirow{2}{*}{$\begin{array}{c}\mathrm{R} / \mathrm{C}- \\
\mathrm{PV} \text { relay }\end{array}$} & OCR & & 37.9 & 37.9 & 41.3 & 31.4 & 31.4 & 40.1 & 25.6 & 25.6 & 37.9 \\
\hline & OCGR & & 9.3 & 17.4 & 21.2 & 11.4 & 11.4 & 19.1 & 4.7 & 8.4 & 18.0 \\
\hline
\end{tabular}




\subsubsection{COORDINATION TIME INTERVAL BETWEEN S/S RELAY AND CUSTOMER RELAY}

Coordination time interval between S/S relay and customer relay should be maintained by more than 17Cycle according to technical guidelines of KEPCO. In order to evaluate a proper coordination between protection devices in Case I, coordination time intervals of OCR and OCGR between S/S relay and R/C are obtained as shown in Fig. 6 and Table 8, based on the modeling of Off-DAS S/W. The coordination time interval of OCR between S/S relay and customer relay is determined by 272.6Cycle as shown in Fig. 6(a) and one of OCGR is 44.2Cycle in Fig. 6 (b). Therefore, it is confirmed that coordination time intervals of OCR and OCGR are kept within proper values according to technical guidelines of KEPCO. For 3 operation modes, coordination time intervals between protection devices are obtained as shown in Table VIII. In Table VIII, it is found that coordination time intervals between $\mathrm{S} / \mathrm{S}$ relay and $\mathrm{R} / \mathrm{C}$ for 3 operation modes are kept within proper values according to technical guidelines of KEPCO regardless of introduction capacity of PV system.

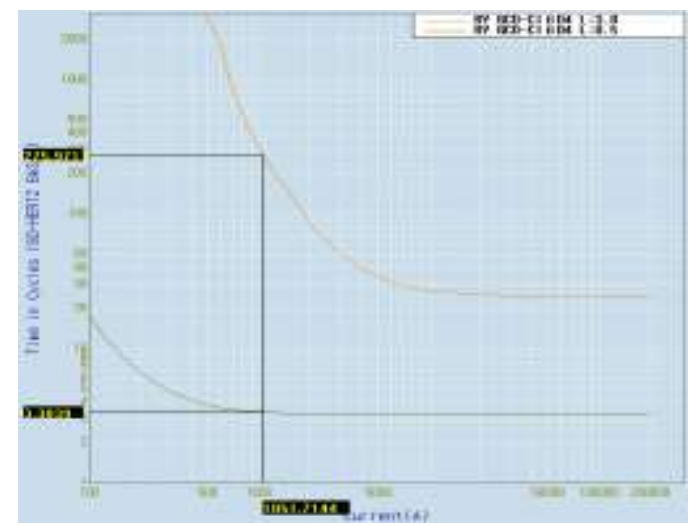

(a) OCR

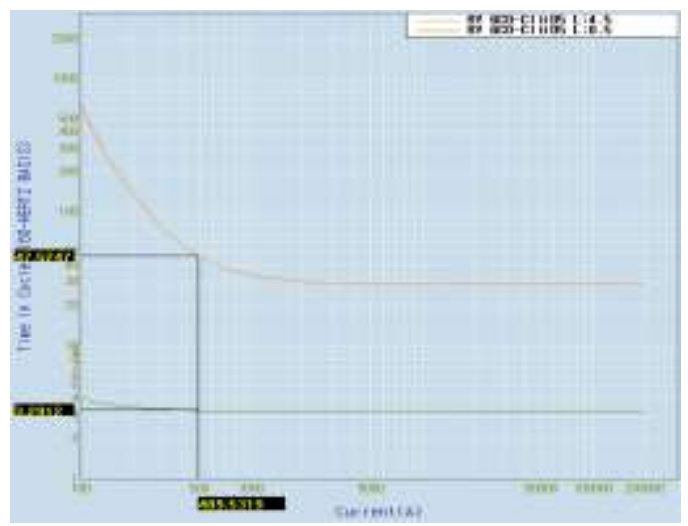

(b) OCGR

Fig. 6 Coordination time interval between S/S relay and customer relay

Table VIII. Coordination time interval between S/S relay and customer relay R/C

\begin{tabular}{|c|c|c|c|c|c|c|c|c|c|c|c|}
\hline \multirow{2}{*}{\multicolumn{2}{|c|}{$\begin{array}{c}\text { Capacity of PV } \\
\text { system(MW) }\end{array}$}} & \multicolumn{10}{|c|}{ Time interval of protection devices(cycle) } \\
\hline & & \multirow{2}{*}{$\begin{array}{c}\mathbf{0} \\
\text { Case } \\
\text { I }\end{array}$} & \multicolumn{3}{|c|}{1} & \multicolumn{3}{|c|}{3} & \multicolumn{3}{|c|}{5} \\
\hline \multicolumn{2}{|c|}{ Operation mode } & & $\begin{array}{c}\text { Case } \\
\text { I }\end{array}$ & $\begin{array}{c}\text { Case } \\
\text { II }\end{array}$ & $\begin{array}{c}\text { Case } \\
\text { III }\end{array}$ & $\begin{array}{c}\text { Case } \\
\text { I }\end{array}$ & $\begin{array}{c}\text { Case } \\
\text { II }\end{array}$ & $\begin{array}{c}\text { Case } \\
\text { III }\end{array}$ & $\begin{array}{c}\text { Case } \\
\text { I }\end{array}$ & $\begin{array}{c}\text { Case } \\
\text { II }\end{array}$ & $\begin{array}{c}\text { Case } \\
\text { III }\end{array}$ \\
\hline \multirow{2}{*}{$\begin{array}{c}\text { S/S relay- } \\
\text { customer relay }\end{array}$} & OCR & 361.6 & 324.2 & 324.2 & 375.4 & 272.6 & 272.6 & 361.6 & 231.3 & 231.3 & 361.6 \\
\hline & OCGR & 263.7 & 140.6 & 1406. & 59.8 & 100.1 & 44.2 & 56.9 & 80.7 & 39.6 & 56.9 \\
\hline
\end{tabular}

\section{CONCLUSION}

This paper presents 3 operation modes of protection devices considering the operation conditions of PV system to obtain setting values of protection devices and proposes algorithm to calculate optimal protection coordination time interval. Firstly, setting values of all of protection devices with 5MW PV system are almost identical with ones of 1MW except for time delay tap for OCGR of S/S relay and CT ratio of customer relay, therefore it is found that there is no change depending on introduction capacities of PV system. And also, it is found that coordination time intervals of all protection devices for 3 operation modes are kept within proper values according to technical guidelines of KEPCO until $3 \mathrm{MW}$ of PV system. In addition, it is confirmed that protection coordination of OCGR between R/C and customer relay, R/C and PV customer relay for Case I are not proper if introduction capacities of PV system are more than 5MW. Furthermore, because protection 
coordination of OCGR between $\mathrm{R} / \mathrm{C}$ and customer relay, $\mathrm{R} / \mathrm{C}$ and $\mathrm{PV}$ customer relay for proposed modes(Case II and Case III) are kept within proper values according to technical guidelines of KEPCO for 5MW PV system, it is confirmed that the proposed operation modes(Case II, Case III) are useful and effective to protection coordination in the distribution system with PV system compare to Case I.

\section{ACKNOWLEDGMENTS}

This work was supported by the Power Generation \& Electricity Delivery Core Technology Program of the Korea Institute of Energy Technology Evaluation and Planning (KETEP) granted financial resource from the Ministry of Trade, Industry \& Energy, Republic of Korea (No. 20182410105070).

\section{REFERENCES}

[1] Seong Ho Sung, Sk. Moulali, P. Prashanth, "Power Distribution Line Fault Detection using Micro Controller", International Journal of Smart Home, vol. 11, no. 8, (2017): 1-8.

[2] V. Mohanbabu, Sk. Moulali, Ju Chan Na, Peng Cheng, "SFCL for Energy Storage Protection in a Power Distribution System", International Journal of Reliable Information and Assurance, vol. 4, no. 1, (2016): 15-24.

[3] Shaik Moulali, K. V. Siva Reddy, "Design and Development of Efficient Standalone Photovoltaic System Using Matlab/Simulink", International Journal of Computer-aided Mechanical Design and Implementation, vol. 2, no. 2, (2016): 1-6.

[4] Dongha Shin, Changbok Kim, "Short-Term Photovoltaic Power Generation Forecasting by Input-Output Structure of Weather Forecast Using Deep Learning", International Journal of Software Engineering and Its Applications, vol. 12, no. 11, (2018): 19-24.

[5] Wei Wei, Li Suo, Xue Peng, "Research on Transformer Fault Diagnosis and Multi Variable Parameter Decision Model", Asia-Pacific Journal of Advanced Research in Electrical and Electronics Engineering, vol. 1, no. 1, (2017): 47-54.

[6] Ji-Hyun Park, Byung-Mok Kim, Hu-Dong Lee, Yang-Hyun Nam, Dae-Seok Rho, "A Study on Control Algorithms of Efficiency Improvement Device for PV System Operation using Li-ion Battery", Journal of the Korea Academia-Industrial cooperation Society, vol. 19, no. 10, (2018): 590-597.

[7] Soon-hwan Kwon, Hu-dong Lee, Yang-hyun Nam, Dae-seok Rho, "Optimal Operation Algorithm of Protection Devices in Distribution Systems With PV System", Journal of the Korea Academia-Industrial cooperation Society, vol. 19, no. 5, (2018): 17-26.

[8] Kyung-Sang Ryu, Byung-Ki Kim, Dae-Jin Kim, Moon-Seok Jang, Dae-Seok Rho, Hee-Sang Ko, “A study on Protection Coordination Method for Electric Vehicle Charging Facility based on the Wireless Power Transmission", Journal of Korea Academia-Industrial cooperation Society, vol. 18, no. 9, (2017): 42-51.

[9] Dae-Seok Rho, "A Study on the Fault Characteristics of Wind Power in Primary Feeder", Journal of Korea Academia-Industrial cooperation Society, vol. 13, no. 3, (2012): 1288-1295.

[10] Guideline for Interconnection of Distributed Generation System in Distribution Systems, KEPCO, (2012).

[11] So-Hee Kim and Dae-seok Rho, "Evaluation Algorithm for Coordination Protection Between Recloser and Distributed Generation Relay", Korea Academia-industrial cooperation society, announced Spring conference proceedings in 2010, (2011): 69-72.

[12] Dae-seok Rho, "Countermeasures on bi-directional Protective Device Coordination of smart grid connected to new energy generation", The world of electric, vol. 5, no. 9, (2010): 39-43.

[13] Byeon-Gi Kim, Jae-Beom Park, Kyeong-Sang You, Dae-Seok Rho, "Optimal Operation Methods of Protection Devices in Distribution Systems with PV Systems", The Korean Institute of Electrical Engineers, vol. 60, no. 8, (2011): 1485-1491. 